\title{
How does a painkiller harm the heart?
}

t was Garret FitzGerald, the chair of pharmacology at the University of Pennsylvania, who first proposed that the painkiller Vioxx and its cousins might cause heart attacks by tipping a crucial hormonal balance. So neither of two attention-grabbing data sets published this month has come as a great surprise to him, despite the implications the data are likely to have for the 11,500 lawsuits from former patients that dog the drug's manufacturer, Merck.

One study, published in the Canadian Medical Association Journal ${ }^{1}$, shows that Vioxx, now withdrawn, caused heart attacks within days of users first taking it. The other data, released last week by Merck, suggest that subjects remained at increased risk of heart attack and stroke for a year after they stopped taking the drug $^{2}$.

"These data are extremely interesting if you're a lawyer, but scientifically and mechanistically they show exactly what you'd expect," says FitzGerald.

Others disagree. Nobody expected the Merck results, says Steven Nissen, a cardiologist at the Cleveland Clinic in Ohio. "We all thought that if you stopped the drug, the risk would go away. These data suggest there may be more longstanding injury to blood vessels."

The difference of opinion reflects uncertainty over exactly how heart attacks and strokes are caused by Vioxx (rofecoxib) and related drugs, which all work by inhibiting an enzyme known as cyclooxygenase-2. It is widely accepted that these 'COX2 inhibitors' exert their effects in part by suppressing prostacyclin - a product of the COX2 enzyme. Prostacyclin plays a key role in mediating pain and inflammation: the drugs were developed to combat inflammatory diseases such as arthritis.

\section{Off balance}

But studies in mice have shown that prostacyclin also acts as a general restraint on platelet activation, and on factors that accelerate hardening of the arteries (atherosclerosis), boost blood pressure and activate blood clotting. Key among these factors is a molecule called thromboxane. Crudely put, prostacyclin and thromboxane normally balance each other's opposing effects. Introducing a COX2 inhibitor can tip the balance dangerously toward thromboxane, raising blood pressure,

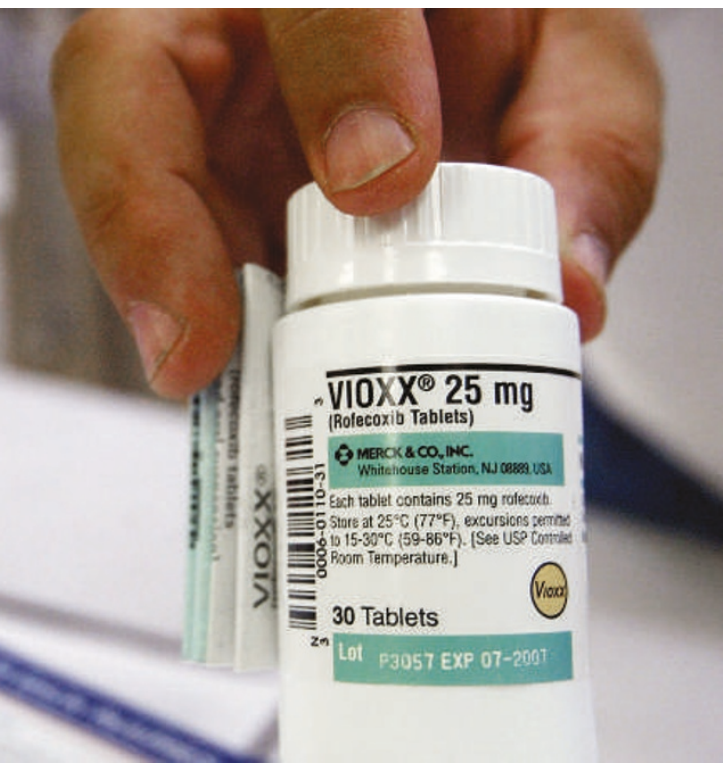

Pulled: after the scandal of withdrawal, Vioxx is unlikely to go back on sale. But its sister drugs may have a future.

possibly hardening arteries and certainly promoting heart-attack and stroke-causing clots in some people.

The Canadian study, which found that Vioxx's adverse effects kicked in almost immediately, fits neatly with this theory. There is an established link between prostacyclin suppression and excessive clotting, points out Eric Topol, a geneticist at Case Western Reserve University in Cleveland. "If you start to suppress prostacyclin, you could see a clot form relatively quickly. Why would you need months or a year to see that?"

The Merck data are more difficult to explain. FitzGerald says they fit with his work in mice, which shows that COX2 inhibitors can cause atherosclerosis - not an injury that would recede rapidly once the offending drug is stopped. But this has not been demonstrated in humans.

"I don't think it's well-established" that Vioxx causes atherosclerosis in people, says Nissen. "But Garret's been right about a lot. He may be right about this."

Frank Ruschitzka, a cardiologist at the University Hospital in Zurich, who has studied Pfizer's Celebrex, another COX2 inhibitor, says it is a mistake to draw any mechanistic conclusions from Merck's report. The study it is drawn from, he notes, was not designed to examine heart attacks 3 . "We don't know the mechanisms," he says. "So everyone involved should just lower their voices."

Ruschitzka has designed a trial of 20,000 subjects to be launched later this year, with Nissen as principal investigator. It will compare the incidence of heart attacks, strokes and cardiovascular deaths in subjects taking Celebrex (celecoxib) with those using the traditional anti-inflammatories ibuprofen and naproxen. Only such a huge, randomized, head-to-head controlled trial paid for by Pfizer at a cost of hundreds of millions of US dollars - will allow the science of the side effects to be truly sorted out, he says.

Ruschitzka believes that more mechanisms are at work than the balancetipping theory admits. For instance, in one recent paper, he showed that Celebrex reduces expression of a protein that initiates coagulation ${ }^{4}$. Vioxx doesn't have this effect. "If FitzGerald tells us it's just one mechanism, he's wrong," says Ruschitzka.

Others, including Topol, believe that a minority of individuals may have a genetically determined sensitivity to Vioxx. But this could be pinned down only by a genome-wide study comparing those who develop clotting with those who do not. And that's not a study that Pfizer or Merck are rushing to sponsor.

The quest to clear these murky waters isn't just academic, even if Vioxx itself is unlikely ever to be resurrected. It is hoped that other COX2 inhibitors may eventually treat diseases as diverse as colon cancer and Alzheimer's. And it is therefore vital to flesh out the mechanism of their cardiac dangers, so the risk-benefit equation is understood before the drugs saturate new markets.

As for former Vioxx patients, Nissen says they should all be closely monitored for at least a year. He tells his own patients that their risk of heart attack has been almost doubled, and that "they should do everything they can to control their risk factors".

\section{Meredith Wadman}

1. Lévesque, L. E., Brophy, J. M. \& Zhang, B. Can. Med. Assoc. J. 174, doi:10.1503/cmaj.051679 (2006).

2. Merck APPROVe report (2006); www.merck.com/ newsroom/pdf/APPROVe_Study_Summary_Report.pdf

3. Bresalier, R. S. et al. N. Engl. J. Med. 352, 1092-1102 (2005).

4. Steffel, J. et al. Circulation 111, 1685-1689 (2005). 